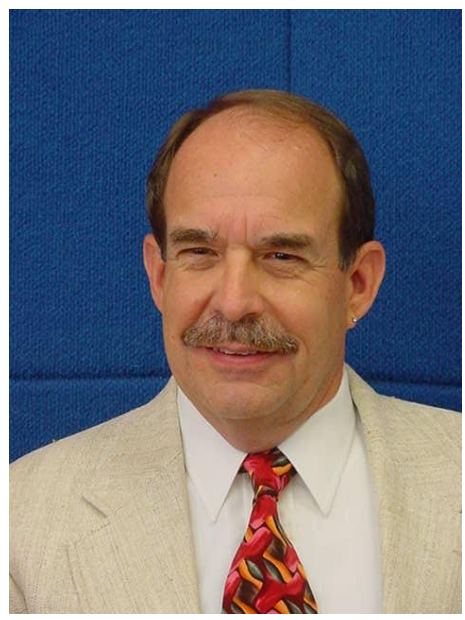

\title{
THE PAUSE THAT REFRESHES: \\ A STUDY OF SELF-FUNDED LEAVE
}

\author{
Dale S. Furbish
}

Auckland University of Technology

\begin{abstract}
Self-funded leave programmes provide a time resource to employees so that they can pursue interests outside their normal employment. This article reports the results of qualitative research conducted on 16 workers who completed a self-funded leave programme. Semi-structured interviews were used to explore participants' motivations to enrol in the self-funded leave programme, how the leave contributed to work-life balance through development of non-work life roles, and difficulties that arose during participation in the self-funded leave programme. Results reveal that participants did use selffunded leave to improve their work-life balance and augment other life-roles. However, unpredicted events influenced how the leave time was actually used, which was often different from original plans and goals. Adult transition theory is used to conceptualize the process of participating in self-funded leave and to suggest how employees who undertake self-funded leave can be best supported by employers.
\end{abstract}

\section{Introduction}

Imagine that your employer offered you a year's leave. And that you would continue to receive most of your salary. What would you do during the year? Travel? Complete a home building project? Spend time with the family? Fulfil a lifelong dream? Do "nothing"?

This scenario describes the potential outcomes for employees who participate in self-funded leaves. Selffunded leave is a scheme whereby an employee contributes a potion of salary over set time to a fund held by the employer. At the end of the agreed contribution period, leave is granted to the employee. During the leave, the employer continues to distribute the salary, which is resourced from the employee's self-contribution.

A typical structure for self-funded leave plans is for an employee to set aside $20 \%$ of salary for 4 years. During the $5^{\text {th }}$ year, the employee takes a leave of absence and receives $80 \%$ of the most recent salary (i.e., the salary received during the $4^{\text {th }}$ year). This scheme is often called the 4 for 5 plan. Another option is for an employee to set aside $20 \%$ of salary for $2 \frac{1}{2}$ years, then take a 6 month leave of absence, again at $80 \%$ salary for the term of the leave. This variant is known as a 2 for $2 \frac{1}{2}$ leave.

Although self-funded leave is not widely available in New Zealand, it is common in some countries. For example, self-funded leave is available to all Canadian government employees. Where available, self-funded leave is often seen as a way of "harmonizing the long-term career and personal goals of employees" and "increasing the flexibility of departments in using resources" (Treasury Board of Canada, 1997).

Self-funded leave is a means for addressing employees' work-life balance. Lack of time is frequently identified as the confounding issue for employees to pursue out-of-work goals.

Work-life balance has received much attention in contemporary career literature (Gambles, Lewis, \& Rappoport, 2006; Glynn, Steinberg, \& McCartney, 2002; Greenhaus \& Beutell, 1985; Hall, 1990; Halpern \& Murphy, 2005; Pocock, 2003). Discussions about work-life balance validate the multi-faceted lives that workers live and the difficulties that can arise when work roles displace other life roles. Neault (2005) asserted that:

Regardless of one's personal definition for balance, most people know when they are out of balance; they are constantly tired, feel as if their choices are limited, have minimal control, and are no longer able to effectively manage their lives. (p. 1) 
Employers have a stake in reducing employee work-life role conflicts. Allen, Herst, Bruck, and Stutton (2000) found that such conflicts result in negative consequences not only for individual employees, but also for the employing organization. Low motivation, absenteeism, and low productivity are but some of the negative consequences when work-life balance is not addressed.

Numerous strategies exist for an employer to promote balance. Employers may offer various benefits such as flexible scheduling, telecommuting, day-care, or eldercare assistance (Lobel \& Kossek, 1996). However, for many employees, free time is often the critical factor to achieve work-life balance.

Some employers have developed sabbatical programmes that allow employees to pursue interests away from normal employment. However, in comparison to self-funded leave, sabbaticals have "strings attached." Sabbaticals are designed to allow an employee to pursue a workrelated/professional interest and are therefore usually available only to professionals or senior staff within an organization. Employees typically qualify for a sabbatical based upon length of service, rank, etc. Also typical of a sabbatical, some sort of academic or professional output is expected as a result of the sabbatical. Last, since (reduced) salary is often paid by the employer during the sabbatical, there is a requirement that the sabbatical taker returns to employment for a specific period or repay the salary.

Sabbaticals are available in a variety of employment settings such as universities (Kimball, 1978), business (Carr \& Tang, 2005), secondary schools (Gaziel, 1995), nursing (Keleher, 1993), and libraries (Hubbard, 2002). They have been associated with a number of positive outcomes including increased job satisfaction, personal and professional growth, focused time for improving teaching, research, and service, new perspectives and attitudes, improved mental and physical health, increased energy and enthusiasm, and producing scholarly/creative products (Benshoff \& Spruill, 2002; Boening \& Miller, 1997; Cook , 1994; Sima, 2000; Zahorski, 1994). Nevertheless, the structure and requirements of sabbaticals do not provide the time resource to employees for pursuing purely personal goals.

Self-funded leave is an alternative to sabbaticals. Rather than being available only to a select number of employees in an organization, self-funded leave is typically available to all employees in an organisation, regardless of length of employment or level of responsibility. Moreover, the complete flexibility permitted for an employee to use selffunded leave for any purpose promotes the attainment of personal goals, with no expectation of job related outcomes.

\section{Method}

In order to examine how employees used self-funded leave plans and to better understand how self-funded leave contributes to work-life balance, a study was conducted on the experiences of a group of university employees who completed either a 4 for 5 or a 2 for $2 \frac{1}{2}$ self-funded leave programme.

Three main research questions were of interest.

Research Question 1: What were the motivations of participants for undertaking self-funded leave and did participants fulfil the purposes of the leave?

Research Question 2: How did participants use the period of self-funded leave to pursue goals and interests that were constrained during full-time employment?

Research Question 3: What problems were experienced by participants during self-funded leave and how could they be best supported during the entire span of preparation, leave, and return to work?

\section{Participants}

Participants of this study were employees of a large urban New Zealand university who had completed a self-funded leave programme. Twenty-two potential participants were identified by the university's human resources office. Of these, 16 agreed to be interviewed. Both teaching and nonteaching employees were represented. Nine of the participants held academic (teaching) contracts and 7 held administrative (non-teaching) contracts. Participants included senior lecturers, librarians, administrative staff, student services staff, and maintenance staff. Ten participants had completed the 2 for $2-1 / 2$ self-funded leave programme and seven had completed the 4 for 5 programme. One participant had completed both options.

\section{Procedure}

A qualitative research approach was employed. Interviews were conducted using a semi-structured interview protocol. Questions used in the interview were designed to solicit accounts of the entire self-funded leave experience, commencing with the initial decision to participate through completion of the leave and return to work. Written notes were made during the interview and the interviews were audio recorded.

\section{Results}

Analysis of the data indicated the following findings for each research question.

\section{Research Question 1}

A variety of motivations to enrol in the leave programmes were expressed. Personal renewal was a goal for many of the participants. Participants reported "burn-out" in their position, needing a break, opportunity to reenergize their 
career, restore work-life balance, and reclaim career on own terms.

\section{One participant expressed:}

"The 4 for 5 gave me a break from the routine. I was feeling burned out and not making the effort that I wanted to make in my work. I could have taken a sabbatical, but with a sabbatical, I would have had to work on an academic project during the time away. I didn't want that sort of expectation hanging over me. I just wanted to have time to do the things that I wanted to do."

Other participants expressed more exact goals for enrolling in the self-funded leave programme. Specific objectives for the self-funded leave included travelling overseas, overseeing construction of a house, completing an academic qualification, fulfilling a life-long goal, writing a book, previewing retirement, and immersing a young daughter in the family's native culture.

Another participant reported:
"Since I was a child, I have wanted to ride on the Trans-Siberian railway. I read a book about the trip when I was 10 years old and set the goal that one day I would make the journey. Of course, attending university, getting married and working never provided me with the opportunity to fulfil my dream. When I learned about the 4 for 5 programme, I knew it was what I wanted to do. And it worked out. The year I was on leave was used to travel in Asia and then take the Trans-Siberian trip. I took tons of pictures and have wonderful memories of my travel. I have enrolled now in the 2 for 2-1/2 programme. I'm not sure what I will do this time, but knowing that I have some more extended leave coming up helps my enthusiasm at work."

All participants reported that self-funded leave was a positive experience and that they were satisfied. They also reported beneficial outcomes from the leave and felt that they returned to work with greater motivation and employer loyalty. However, specifics of how the leave time was used did not always coincide with pre-leave plans. Some of the participants modified how leave time was used because of unforeseen events. Examples were a marriage separation, illness of family members, personal illness and unanticipated expenses associated with travelling.

\section{Research Question 2}

Some differences in the specific goals of the participants were linked to job responsibilities. Participants on teaching contracts were more likely to engage in academic pursuits such as completing a degree or writing a book or journal article. However, there were many commonalities between participants on teaching contracts and administrative nonteaching contracts.

A participant on an academic contract stated:
"I had been working in a high pressure, time consuming (teaching) job for twenty years. My family grew up without me during this time. I felt like I just needed a break from the routine and have the time to do what I wanted to do. Originally I planned do some academic writing and revise my book during my self-funded leave. But, right before my leave began, my daughter had a baby. So, my year's leave allowed me to spend time with my daughter and be a grandmother. This was great because it helped me establish a relationship with my daughter and my grandchild that wouldn't have been possible if I had been working. And, I was still able to do my book revisions. So, it was a win-win situation. I accomplished both personal and professional goals. I am now happy to be back at work and feel refreshed and re-energised."

A maintenance staff worker on an administrative contract reported:

"I immigrated to New Zealand from Turkey 15 years ago. Since I have been here, I have married and started a family. My children have never been to Turkey, so I used the time from my 4 for 5 to take them there to meet their relatives and learn Turkish culture. I don't think they would have ever had the opportunity to really experience their culture otherwise. It gave me the time and money to expose my children to an important part of their background. I am happy that I have been able to do this for my family and it makes me feel good about myself."

In all cases, participants engaged in activities that would not have been possible when working full-time. Shifts from worker roles to roles that would have not been otherwise possible during full-time employment were found in each participant's story. Such shifts were supportive of achieving work-life balance.

\section{Research Question 3}

Finances were reported as the greatest concern while participating in self-funded leave. Because self-funded leave programmes require participants to contribute $20 \%$ of salary during the build up period (either $2 \frac{1}{2}$ or 4 years depending on the programme option) and receiving reduced salary during the leave period itself (a further 6 or 12 months), participants experienced lower salary over a significant period. Living on $80 \%$ of salary during the leave lead-up period was difficult for some of the participants. Indeed, a few participants reported that they began the programme and had to withdraw due to financial reasons before they eventually re-enrolled for the programme and completed the leave. Having the financial resources to fulfil goals during the leave period was difficult and resulted in modifying activities during the leave period. Examples were lessening travel while on leave, or taking other employment during the leave period to meet financial obligations. 
An example was:

"I intended to use my year's leave to preview retirement. I am getting close to when I planned on retiring and I thought the year away from work would let me test what retirement would be like and if I would enjoy it. I quickly discovered that things were a lot more expensive than what I had planned for. I did some overseas travelling and intended to be away for 9 months. But, I ran out of money much sooner. After about 4 months, I returned to New Zealand. Even visiting friends in New Zealand took more financial resources than I anticipated. I have now decided to postpone my retirement and continue to work. I would still like to retire, but now realize that I will need to save a lot more if I want to do the things I'd like to."

The period of leave had major impacts on the life roles of all participants. As would be expected, each reported a reduction in their role of worker (employee) and some missed the social relationships and collegiality from work. However, since self-funded leave does not prohibit employment during the leave, some participants did work in other jobs. None of the jobs were full-time. The motivation for some participants who took another job while on leave was to increase income. Others who took other employment while on leave wished to gain experience in another occupation.

Unplanned events during the leave resulted in increased salience of some life roles for several participants. In these instances, the role of grandparent was highlighted when their children became parents during the participants' leave. Roles of child (son/daughter) became more important for some participants whose parents became ill and required care.

Leisure roles were augmented and leave takers used leave time to learn new past-times such as golf and Tai Chi. Student roles for some became more salient as a result of studying to complete an academic qualification or through self-interest study of other languages and political science. Changes in community roles were typified by increases in volunteer activities. Leave provided time for some to complete household projects, thus modifying their homemaker role.

Some participants reported negative aspects of being away from the university for an extended period. A few felt that changes occurred in their departments while they were on leave and they had no input to these changes. Others suggested that being on an extended leave was viewed negatively by their colleagues and supervisors and was an impediment to professional career progression. A few participants who had teaching roles and who were on leave during the first 6 months of the academic years reported difficulties with re-entering teaching in the middle of the year. Although not wide spread, feelings of dread and adjustment difficulties were reported by some participants when they returned to a work schedule after the flexibility of self-controlled time utilization.
Participants also identified advantages and disadvantages to their employer as a result of their self-funded leave. Participants suggested that staff who replaced them while they were away gained valuable experience. By trialling new job roles, replacement staff gained insight into their career progression and possible succession into future job roles.

\section{A participant reported:}

"I was the programme leader when I took my leave. Before I began my leave, one of my colleagues volunteered to serve in this role while I was away. As it worked out, this person enjoyed the job; much more than I did. When I came back to work, I re-evaluated my professional goals and decided that I wanted to have more time to teach and write and to be less involved in department management. The Head of School supported my decision and felt good that he had a replacement for me who already had a year's experience in the role."

Assistance with financial planning emerged as the most frequently requested support for self-funded leave. Many participants reported that they wished that there was more information available about living on a reduced income and budgeting. It was suggested that the Human Resources Office could organize financial workshops for those planning self-funded leave and that the workshops could use the expertise of various staff who had backgrounds in financial planning. Also there were suggestions for workshops led by employees who had completed selffunded leave. Self-funded leave "alumni" were considered to have insight to the sort of issues that can arise during self-funded leave and also possess useful strategies for coping and adapting when negative issues arise. Although not frequently suggested, a few participants also recommended that counselling for reintegration back into work roles be available to those completing their leave.

\section{Discussion}

Work-life balance is achieved when life roles other than employee are also fulfilled. Super's (1976) notion of life roles provides a useful framework for conceptualising work-life balance within a self-funded leave context.

Super (1976) proposed the "life-career rainbow" model to comprehensively convey the structure and nature of career. Fundamental to this model was recognition that career is comprised of multiple life roles, with worker being only one that a person simultaneously occupies. Other life roles that an individual may inhabit are child, student, leisurite, citizen, spouse, parent and homemaker, and pensioner. Super noted that other life roles might also be identified. Sibling, worshiper, lover, reformer, criminal are other roles that he suggested. Regardless of the specific roles and the sequence in which they appear during life, "The constellation of interacting, varying roles constitutes the career" (Super, 1980, p. 284). 
Enactment of the various roles that an individual may possess at a given time also has a temporal aspect. For example, not everyone marries and some people die before retirement. The saliency, or importance, that each life role has for an individual at a given time varies. For example, the role of parent is usually of greater salience when children are young and living at home than after they leave home. Because people fulfil multiple roles, the time spent in one role takes away time from others. Super recognized that the "The number of hours in day, the number of days in a month and in a year...set limits to the degree to which the simultaneous and sequential proliferation of roles produces role conflict or results in self-actualisation and satisfaction" (Super, 1980, p. 287). Although Super did not use the terminology, his statement is seminal for consideration of work-life balance.

The self-funded leave programme provided an increased time resource to fulfil life roles other than worker. Time for discretionary role fulfilment emerged as the most valuable resource afforded by self funded leave.

Yet, self-funded leave generates role transitions are sometimes problematic. A number of participants reported difficulty when making role transitions during the leave.

Goodman, Schlossberg, and Anderson (2006) proposed the 4S (situation, self, support, and strategies) model for helping adults with transitions. Each " $\mathrm{S}$ " is a variable that can either contribute to the ease or to the difficulty of the transition.

The 4S model would suggest that information about the Situational aspects of self-funded leave be gathered by participants before taking leave. Situational understanding would likely contribute to the ease of transition and could be gained from discussions with others who have completed a self-funded leave. Understanding the pros and cons of self-funded leave would likely assist employees best prepare for the experience.

Consideration of the Self would also likely enhance a selffunded leave. Reflecting on personal goals for the time away from work is useful for maximizing the time resource provided by self-funded leave.

Surveying Support resources also contributes to positive outcomes for self-funded leave. Anticipating financial resources, both during the lead-up period and the leave period itself is likely to reduce the "shock" of living on a reduced income. Many participants felt that finances diminished the fulfilment of goals they planned during the leave. However, Support extends beyond financial resources. A number of participants noted the importance of emotional support from family and significant others during the leave. In many cases, family reorganized their lives during an employee's self-funded leave. Changes to family routines and partners' employment were necessary because of travel plans. But also some participants reported that spending more time with family introduced new family dynamics that necessitated adjustment by all family members.
The final element of the $4 \mathrm{~S}$ model, Strategies, seemed to be a necessary and useful element for successful transitions during self-funded leave. Planning and developing abilities to adapt to the inevitable unforeseen events that occurred in most every report increased the likelihood of a good outcome for the self-funded leave.

Timing of a transition is also identified by Goodman et al. (2006) as a critical. Essentially, the timing consideration asks the basic question, "Is this a good time in my life for a transition to occur?". Those who planned their self-funded leave for a time when other "big events" in their lives were not occurring seemed to have the most positive experiences during their leave.

However, unforeseen changes in personal circumstances can occur, regardless of planning. Self-funded leave programmes require a long-term time commitment, during which negative events can arise. Therefore, personal flexibility and situational adaptability are facilitative traits to make the best of negative events should they arise during leave.

\section{Conclusions and Summary}

The results of this study support the notion that self-funded leaves of absence are win-win situations for employers and employees. Self-funded leave provides employees with the time to achieve personal and, in some cases, professional goals. The time afforded to an employee by self-funded leave impacts the life roles of the employee and provides the means to increase the salience of roles other than worker (employee). Self-funded leave was also reported to contribute to motivation and loyalty.

Employers can also benefit from offering self-funded leave to employees. Employers gain the good will and revitalization of their workforce. Employers who provide self-funded leave are seen as "employers of choice", important for attracting new employees. Unlike most other leave programmes, self-funded leave requires little financial commitment from the employer. Employees, rather than employers, fund the leave. Employers benefit from the development of replacement staff when an employee is on self-funded leave. Replacement staff engages in job duties that provide work trials, skills development, and position experience that are useful for organizational succession planning, at no additional cost to the employer.

Despite the reported benefits of self-funded leave, the current study revealed that self-funded leave opportunities are not without potential issues for employees who participate. Financial difficulties brought on by reduced salary during the lead-up period and the leave itself were problematic for a number of the self-funded leave takers interviewed in this study. Participants also discussed concerns about modified role relationships at work and with family. Unplanned events occurred during the leave period of most participants. Flexibility, adaptation, and goal modification were necessary. Although most 
participants were capable of responding to challenges brought on by the experienced transitions, it was evident that some participants would have benefited from additional employer support.

The results of this study suggest that self-funded leave is a viable and attractive scheme for both employers and employees. The current investigation occurred in an academic setting. Future research that studies the development and implementation of self-funded leave in other employment environments is suggested.

\section{References}

Allen, T., Herst, D., Bruck, C., \& Sutton, M. (2000). Consequences associated with work-to-family conflict: A review and agenda for future research. Journal of Occupational Health Psychology, 5, 278-308.

Benshoff, J., \& Spruill, D. (2002). Sabbaticals for counselor educators: Purposes, benefits and outcomes. Counselor Education and Supervision, 42, 131-144.

Boening, C., \& Miller, M. (1997). Research and literature on the sabbatical leave: A review. (ERIC Document Reproduction Service No. ED 414 777).

Carr, A., \& Tang, T. (2005). Sabbaticals and employee motivation: Benefits, concerns and implications. Journal of Education for Business, 80, 160-165.

Cook, J. (1994). Are you on the cutting edge? Teaching Pre $K-8,24,28-29$.

Gambles, R., Lewis, S., \& Rappoport, R. (2006). From work-life balance to socially sustainable work: An international perspective. London UK: Work-life Research.

Gaziel, H. (1995). Sabbatical leave, job burnout and turnover intentions among teachers. International Journal of Lifelong Education, 14, 331-338.

Glynn, C., Steinberg, I., \& McCartney, C. (2002). Work-life balance: The role of the manager. Horsham, UK: Roffey Park.

Goodman, J., Schlossberg, N., \& Anderson, M, (2006). Counseling adults in transition: Linking practice with theory $\left(3^{\text {rd }}\right.$ ed.). New York NY: Springer.

Greenhaus, J., \& Beutell, N. (1985). Sources of conflict between work and family roles. Academy of Management Review, 10(1), 76-88.
Hall, D. (1990). Promoting work/family balance: An organizational change approach. Organizational Dynamics, 18(3), 5-18.

Halpern, D., \& Murphy, S. (2005). From work-family balance to work-family interaction. Mahwah, NJ: Lawrence Erlbaum Associates.

Hubbard, M. (2002). Exploring the sabbatical or other leave as a means of energizing a career. Library Trends, 50, 603-624.

Keleher, K. (1993). Sabbatical leaves for nurse-midwives in clinical practice. Journal of Nurse-Midwifery, $38,165-167$.

Kimball, B. (1978). The origin of the Sabbath and its legacy to the modern sabbatical. Journal of Higher Education, 49, 303-315.

Lobel, S., \& Kossek, E. (1996). Human resources strategies to support diversity in work and personal lifestyles: Beyond the "family-friendly" organization. In E. Kossek \& S Lobel (Eds.), Managing diversity: Human resource strategies for transforming the workplace (pp.221-244). Oxford, UK: Blackwell.

Neault, R. (2005). That elusive work-life balance. Paper presented at the National Consultation on Career Development (NATCON) Canada. Retrieved July 15, 2008, from

http://www.natcon.org/natcon/papers/natcon_pape rs 2005 e5.pdf

Pocock, B. (2003). The work/life collision. Annandale, AU: The Federation Press.

Sima, C. (2000). The role and benefits of the sabbatical leave in faculty development and satisfaction. New Directions for Educational Research, 105, 67-75.

Super, D. (1976). Vocational guidance: Emergent decisionmaking in a changing society. In Proceedings of the eighth seminar of the International Association for Educational and Vocational Guidance. Lisbon, PT: Sociedade Portuguesa de Psicologia.

Super, D. (1980). A life-span, life-space approach to career development. Journal of Vocational Behavior, 16, 282-92.

Treasury Board of Canada Secretariat. (1997). Self funded leave. Ottawa, ON: Author. Retrieved July 15, 2008, from http://www.tbssct.gc.ca/pubs_pol/hrpubs/leave/dwnld/self_fl_e.rt $\underline{f}$ 
Zahorski, K. (1994). The sabbatical mentor: A practical guide to successful sabbaticals. Bolton, MA: Anker. 